\title{
Fractional exhaled nitric oxide (FeNO) measurement in asthma and rhinitis
}

See linked article by de Bot et al. on pg 44

\section{*Artur Gevorgyan1, Wytske J Fokkens ${ }^{2}$}

1 Clinical Fellow, Advanced Rhinology and Skull Base Surgery, Department of Otorhinolaryngology, Academic Medical Centre, Amsterdam, The Netherlands

2 Professor and Head of Department of Otorhinolaryngology, Academic Medical Centre, Amsterdam, The Netherlands

*Correspondence: Dr Artur Gevorgyan, Department of Otorhinolaryngology, Academic Medical Centre, Meibergdreef 9, A2-234, 1105 AZ Amsterdam, The Netherlands

Tel: + 31 (0) 610254047 Fax: +31 (0) 205669662

E-mail: artur.gevorgyan@mail.utoronto.ca

The article by de Bot et al. in this issue of the PCRJ demonstrates that fractional exhaled nitric oxide (FeNO) does not correlate with symptoms or quality of life (QoL) in children with allergic rhinitis (AR) with and without asthma. ${ }^{1}$ Patients were assessed for FeNO, nasal and asthma symptom scores, rhinitis-related QoL and house dust mite-specific immunoglobulin E level. Cross-sectional and longitudinal correlations were sought between these parameters at baseline and after two years. The authors found no or very weak correlations between FeNO levels and nasal symptoms, asthma symptoms or QoL in both groups in both years, and concluded that FeNO is unlikely to be a useful biomarker of the clinical severity of upper or lower airway disease in primary care. These findings are not surprising.

Nitric oxide (NO) is produced endogenously in cells by NO synthase. ${ }^{2}$ Its production is increased in response to inflammatory cytokines, and FeNO is thought to be an indirect measurement of airway eosinophilic inflammation. Initial enthusiasm about FeNO as a marker of airway inflammatory disease ${ }^{3,4}$ has now turned into a more balanced outlook, with it being seen as one of the many indirect outcome measures which still require much fine-tuning before they can find (if ever) broad clinical applicability in primary or secondary care.

The advantages of FeNO testing are non-invasiveness, speed, simplicity, ease of tolerance by children and adult patients with severe airway obstruction, and lack of known risks to the patient. ${ }^{5,6}$ The disadvantages include the expense of purchasing and maintaining equipment, the variability of FeNO measurement between centres, and significant overlap of FeNO levels between populations with and without asthma, which thus far renders it as a research tool only.

The American Thoracic Society (ATS) has approved a set of clinical practice guidelines of FeNO interpretation for clinical applications. ${ }^{5}$ There are recommendations concerning the use of FeNO in asthma, particularly for diagnosis and monitoring of eosinophilic airway inflammation and determining the likelihood of steroid responsiveness, whilst accounting for age and allergen exposure as factors. This contrasts with a limited role for the measurement of nasal NO levels, which, though altered in several diseases (e.g. cystic fibrosis, primary ciliary dyskinesia), cannot be recommended for routine clinical practice. $^{7,8}$

A sample of recent literature supports the observations by de Bot et al. Ciprandi et al. evaluated children with AR or asthma and found a correlation between FeNO levels and change in forced expiratory volume in 1 second $\left(\mathrm{FEV}_{1}\right)$ after bronchodilator testing (bronchial reversibility). ${ }^{9}$ The correlation was moderate for both asthma $(r=0.69)$ and rhinitis $(r=0.54)$. Levels of 34 parts per billion $(\mathrm{ppb})$ of FeNO were predictive of bronchial reversibility. The same group also found a moderate negative correlation between FeNO levels and bronchial hyperreactivity in adult patients with persistent $A R \cdot{ }^{10} \mathrm{~A}$ similar negative correlation was found in children with AR with or without asthma. However, correlations between FeNO and rhinitis or bronchial symptoms were weak ( $r=0.18$ and 0.38 , respectively), agreeing with the present findings of de Bot et al. ${ }^{1,10}$ Also, in children with asthma, FeNO monitoring could predict exacerbations - but at least 3-5 FeNO measurements in the three weeks preceding the exacerbation were needed. ${ }^{11}$

In a study of adult patients, Kalpaklioglu found no difference between the levels of orally exhaled FeNO in AR, non-allergic rhinitis (NAR) and control patients. ${ }^{12}$ NAR with asthma was associated with higher FeNO levels than AR with asthma. Perennial sensitisations caused higher FeNO levels. In contrast, Takeno et al. demonstrated significantly higher oral FeNO levels in patients with AR and vasomotor rhinitis compared to controls. ${ }^{13}$ Significantly higher levels were also recorded for nasal FeNO in AR patients, especially with asthma. However, in AR patients with and without asthma the correlations were weak between nasal symptom scores and oral ( $r=0.303$ ) or nasal $(r=0.356)$ FeNO levels. In a prospective cohort study of children with $A R, N A R$ and without rhinitis, children with $A R$ compared with controls had increased FeNO levels (15.9 ppb vs. $6.6 \mathrm{ppb}$ ), along with several other markers of inflammation. ${ }^{14}$ These levels of FeNO, however, are not considered clinically significant; the current ATS guidelines suggest that only FeNO values $>50 \mathrm{ppb}$ (>35 ppb in children) indicate that eosinophilic inflammation and responsiveness to corticosteroids in asthma are likely, whereas values of 25-50 ppb (20-35 ppb in children) should be interpreted with caution. ${ }^{5}$ Interestingly, FeNO levels in healthy controls tend to vary depending on patient age, lung function, ${ }^{15}$ and gender. ${ }^{16}$ Also, common variants in the NO synthesis pathway genes contribute to variation in FeNO levels in children. ${ }^{2}$ Some of these genetic influences were stronger in children with asthma. Surprisingly, lower FeNO levels have been observed in smokers versus non-smokers. ${ }^{17}$

Like orally-measured FeNO, nasal FeNO has not been found to be predictive of severity of disease and patient symptoms. Bozek et al. 
found no significant correlations between the levels of nasal FeNO and nasal symptom scores in young and elderly patients with seasonal allergic rhinitis. ${ }^{18}$

Several conclusions can be made from the above studies in light of the recent findings by de Bot et al. Firstly, despite reported positive associations between the diagnoses of AR and asthma with FeNO, the correlation between symptom scores and FeNO levels is weak or absent. Secondly, usage of nasal FeNO does not improve the correlation with patient-reported symptoms. Finally, despite several reported correlations with other measures of airway disease, the absolute levels of FeNO are highly varying in different studies, and in some these levels are significantly lower than the ATS-recommended cut-off levels indicating eosinophilic inflammation and responsiveness to corticosteroids.

Therefore, the study by de Bot et al. in this issue of the $P C R J$ is supported by the available literature. The consequence is that FeNO should be delegated as a research tool which does not predict the clinical severity of upper or lower airway disease in children in primary care.

Conflicts of interest The authors declare that they have no conflicts of interest in relation to this article.

Commissioned article; not externally peer-reviewed; accepted 7th February 2013; online 21st February 2012

(c) 2013 Primary Care Respiratory Society UK. All rights reserved http://dx.doi.org/10.4104/pcri.2013.00019

Prim Care Respir J 2013; 22(1): 10-11

\section{References}

1. de Bot CM, Moed H, Bindels PJE, et al. Exhaled nitric oxide measures allergy not symptoms in children with allergic rhinitis in primary care: a prospective crosssectional and longitudinal cohort study. Prim Care Respir J 2013;22(1):44-50 http://dx.doi.org/10.4104/pcrj.2013.00009

2. Salam MT, Bastain TM, Rappaport EB, et al. Genetic variations in nitric oxide synthase and arginase influence exhaled nitric oxide levels in children. Allergy 2011 66(3):412-19. http://dx.doi.org/10.1111/j.1398-9995.2010.02492.x

3. Gruffydd-Jones K, Ward S, Stonham C, Macfarlane TV, Thomas M. The use of exhaled nitric oxide monitoring in primary care asthma clinics: a pilot study. Prim Care Respir J 2007;16(6):349-56. http://dx.doi.org/10.3132/pcrj.2007.00076

4. Hewitt RS, Modrich CM, Cowan JO, Herbison GP, Taylor DR. Outcomes using exhaled nitric oxide measurements as an adjunct to primary care asthma management. Prim Care Respir J 2009;18(4):320-7. http://dx.doi.org/10.4104/ pcrj.2009.00060

5. Dweik RA, Boggs PB, Erzurum SC, et al. An official ATS clinical practice guideline: interpretation of exhaled nitric oxide levels (FENO) for clinical applications. Am J Resp Crit Care Med 2011;184(5):602-15. http://dx.doi.org/10.1164/rccm.9120$11 \mathrm{ST}$

6. Szefler SJ, Wenzel S, Brown R, et al. Asthma outcomes: biomarkers. J Allergy Clin Immunol 2012;129(3 Suppl):S9-23. http://dx.doi.org/10.1016/j.jaci.2011.12.979

7. Alobid I, Benitez P, Valero A, Munoz R, Langdon C, Mullol J. Oral and intranasal steroid treatments improve nasal patency and paradoxically increase nasal nitric oxide in patients with severe nasal polyposis. Rhinology 2012;50(2):171-7.

8. Hellings PW, Scadding G, Alobid I, et al. Executive summary of European Task Force document on diagnostic tools in rhinology. Rhinology 2012;50(4):339-52.

9. Ciprandi G, Tosca MA, Capasso M. High exhaled nitric oxide levels may predict bronchial reversibility in allergic children with asthma or rhinitis. I Asthma 2013;50(1):33-8. http://dx.doi.org/10.3109/02770903.2012.740119

10. Cirillo I, Ricciardolo FL, Medusei G, Signori A, Ciprandi G. Exhaled Nitric Oxide May Predict Bronchial Hyperreactivity in Patients with Allergic Rhinitis. Int Archives Allergy and Immunol 2012;160(3):322-8. http://dx.doi.org/10.1159/000341675

11. van der Valk RJ, Baraldi E, Stern G, Frey U, de Jongste JC. Daily exhaled nitric oxide measurements and asthma exacerbations in children. Allergy 2012;67(2):265-71. http://dx.doi.org/10.1111/j.1398-9995.2011.02734.x

12. Kalpaklioglu $A F$, Kalkan IK. Comparison of orally exhaled nitric oxide in allergic versus non-allergic rhinitis. Am J Rhinology \& Allergy 2012;26(2):e50-4. http://dx.doi.org/10.2500/ajra.2012.26.3717

13. Takeno S, Noda N, Hirakawa K. Measurements of nasal fractional exhaled nitric oxide with a hand-held device in patients with allergic rhinitis: relation to cedar pollen dispersion and laser surgery. Allergology International 2012;61(1):93-100. http://dx.doi.org/10.2332/allergolint.11-OA-0318

14. Chawes BL, Bonnelykke K, Kreiner-Moller E, Bisgaard H. Children with allergic and non-allergic rhinitis have a similar risk of asthma. J Allergy and Clin Immunol 2010;126(3):567-73 e1-8

15. Liu HC, Hsu JY, Cheng YW, Chou MC. Exhaled nitric oxide in a Taiwanese population: age and lung function as predicting factors. Journal of the Formosan Medical Association (Taiwan yi zhi) 2009;108(10):772-7. http://dx.doi.org/ 10.1016/S0929-6646(09)60404-6

16. Kim SH, Kim TH, Sohn JW, Yoon HJ, Shin DH, Park SS. Reference values and determinants of exhaled nitric oxide in healthy Korean adults. J Asthma 2010 Jun;47(5):563-7. http://dx.doi.org/10.3109/02770901003702840

17. van Asch CJ, Balemans WA, Rovers MM, Schilder AG, van der Ent CK. Atopic disease and exhaled nitric oxide in an unselected population of young adults. Ann Allergy, Asthma \& Immunology 2008;100(1):59-65. http://dx.doi.org/10.1016/ S1081-1206(10)60406-1

18. Bozek A, Krajewska J, Jarzab J. Nasal nitric oxide and other diagnostic procedures in seasonal allergic rhinitis: elderly vs juvenile patients. Am J Otolaryngology 2011;32(2):105-08. http://dx.doi.org/10.1016/j.amjoto.2009.11.002 